BMC

Veterinary Research

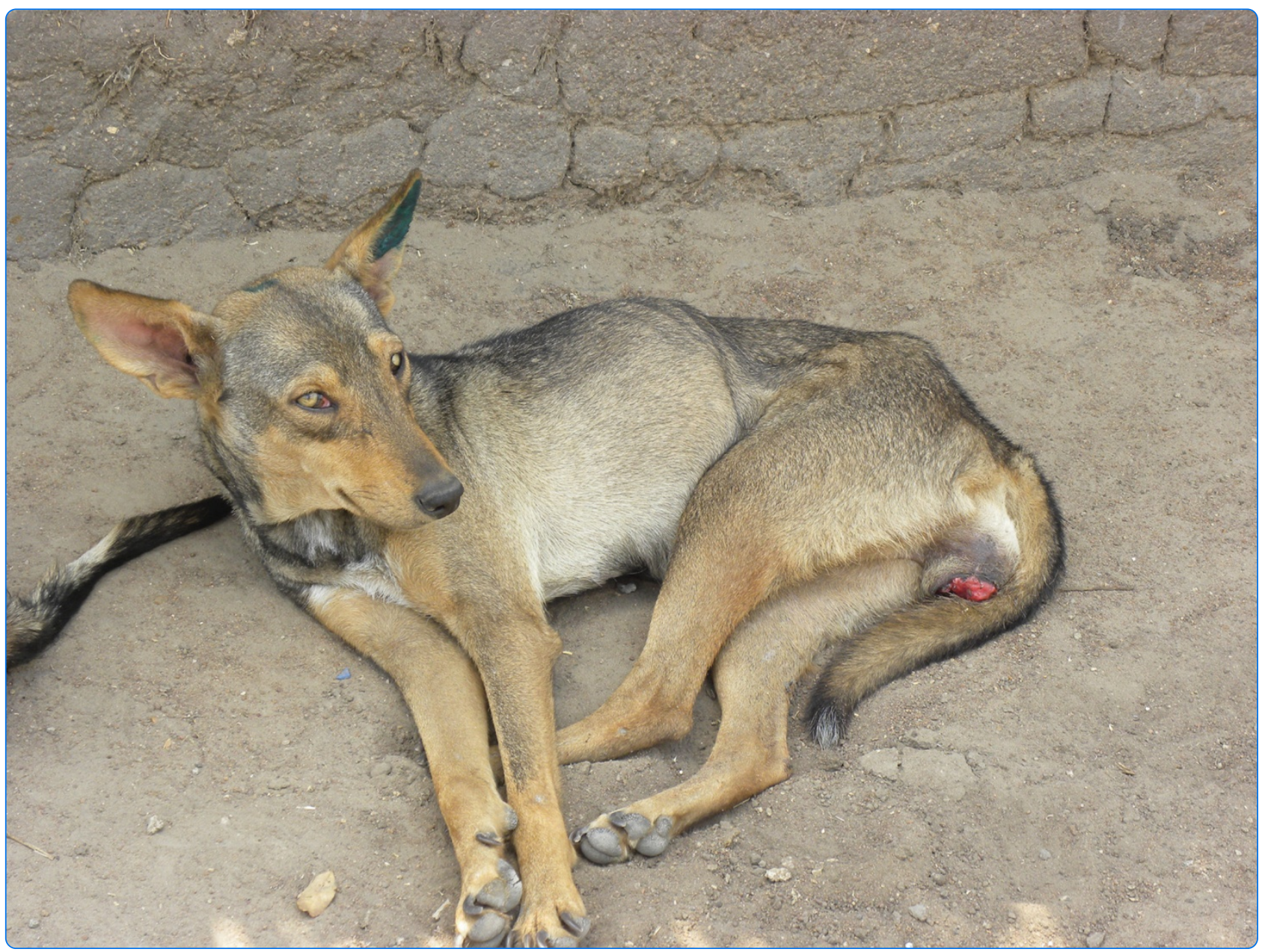

The changing global distribution and prevalence of canine transmissible venereal tumour

Strakova and Murchison 


\title{
The changing global distribution and prevalence of canine transmissible venereal tumour
}

\author{
Andrea Strakova ${ }^{*}$ and Elizabeth P Murchison ${ }^{*}$
}

\begin{abstract}
Background: The canine transmissible venereal tumour (CTVT) is a contagious cancer that is naturally transmitted between dogs by the allogeneic transfer of living cancer cells during coitus. CTVT first arose several thousand years ago and has been reported in dog populations worldwide; however, its precise distribution patterns and prevalence remain unclear.

Results: We analysed historical literature and obtained CTVT prevalence information from 645 veterinarians and animal health workers in 109 countries in order to estimate CTVT's former and current global distribution and prevalence. This analysis confirmed that CTVT is endemic in at least 90 countries worldwide across all inhabited continents. CTVT is estimated to be present at a prevalence of one percent or more in dogs in at least 13 countries in South and Central America as well as in at least 11 countries in Africa and 8 countries in Asia. In the United States and Australia, CTVT was reported to be endemic only in remote indigenous communities. Comparison of current and historical reports of CTVT indicated that its prevalence has declined in Northern Europe, possibly due to changes in dog control laws during the nineteenth and twentieth centuries. Analysis of factors influencing CTVT prevalence showed that presence of free-roaming dogs was associated with increased CTVT prevalence, while dog spaying and neutering were associated with reduced CTVT prevalence. Our analysis indicated no gender bias for CTVT and we found no evidence that animals with CTVT frequently harbour concurrent infectious diseases. Vincristine was widely reported to be the most effective therapy for CTVT.

Conclusions: Our results provide a survey of the current global distribution of CTVT, confirming that CTVT is endemic in at least 90 countries worldwide. Additionally, our analysis highlights factors that continue to modify CTVT's prevalence around the world and implicates free-roaming dogs as a reservoir for the disease. Our analysis also documents the disappearance of the disease from the United Kingdom during the twentieth century, which appears to have been an unintentional result of the introduction of dog control policies.
\end{abstract}

Keywords: Canine transmissible venereal tumour, Transmissible cancer, Epidemiology, Oncology

\section{Background}

The canine transmissible venereal tumour (CTVT) is a naturally occurring transmissible cancer which is spread between dogs by the allogeneic transfer of living cancer cells. The disease is usually transmitted during coitus [1-6] and results in the appearance of tumours most often associated with the external genitalia of male and female dogs (Figure 1). CTVT has been reported in many countries around the world (reviewed in [7-12]) and is, to our knowledge, the oldest and most prolific mammalian somatic cell lineage [13-15].

\footnotetext{
*Correspondence: as2112@cam.ac.uk; epm27@cam.ac.uk

Department of Veterinary Medicine, University of Cambridge, Madingley Road, Cambridge CB3 OES, UK
}

(c) 2014 Strakova and Murchison; licensee BioMed Central Ltd. This is an Open Access article distributed under the terms of the Creative Commons Attribution License (http://creativecommons.org/licenses/by/4.0), which permits unrestricted use, distribution, and reproduction in any medium, provided the original work is properly credited. The Creative Commons Public Domain Dedication waiver (http://creativecommons.org/publicdomain/zero/1.0/) applies to the data made available in this article, unless otherwise stated. the somatic cells of an individual dog that lived several thousand years ago [13-15]. Despite its ancient origin, global populations of CTVT diverged only within the last few hundred years [13-15], suggesting that CTVT spread around the globe relatively recently. Despite numerous historical and contemporary reports of the disease (reviewed in [7-12,16]), no systematic study of CTVT's distribution and prevalence has been performed. Estimating the worldwide distribution and prevalence of a common animal pathogen such as CTVT is a challenging task [17-22]; in most countries the disease is not considered notifiable, and in many areas animals do not have access to veterinary care. Veterinary records are 

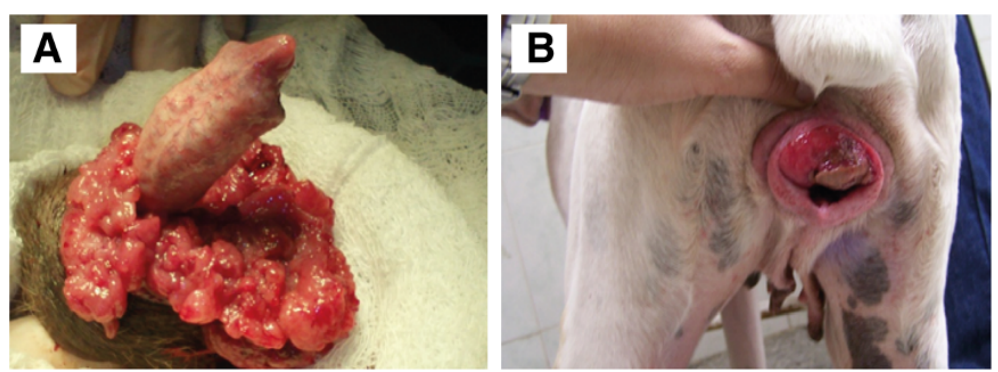

Figure 1 Canine transmissible venereal tumour (CTVT). CTVT affecting (A) a male dog (B) a female dog.

often scant or inconsistent, and variation in CTVT prevalence may exist within countries due to seasonal, demographic or geographic factors. Here, we used a crowdsourcing approach to estimate CTVT's distribution and prevalence by using the internet to contact and source local CTVT prevalence estimates from 645 veterinarians and animal health workers worldwide. We show that the disease's prevalence is linked to national development status and that dog management policies leading to declines in the population of free-roaming dogs may have caused its recent eradication from the United Kingdom. Further insight into the epidemiology of CTVT may help elucidate the timing, route and manner of the disease's global spread. In addition, an understanding of the factors influencing CTVT distribution and prevalence may inform policy decisions for CTVT control.

\section{Results}

\section{Historical worldwide CTVT distribution}

We initially analysed the published literature in order to understand the historical distribution of CTVT. We found 317 reports of primary naturally occurring CTVT cases in the published literature (see Additional file 1), including case reports, experimental reports and retrospective studies. These records provide evidence of CTVT on all six inhabited continents and range in date from 1810 until the present time (see Additional file 1 and Additional file 2). The earliest known record of CTVT is from London in 1810, where it was noted as one of only two cancers known to afflict dogs [23]. We found evidence that CTVT was present prior to 1910 in the United States [24,25], France [26], Germany [27-33], Italy [34], the United Kingdom [2,4,6,35-37], Japan [38] and Papua New Guinea [39]. A 1906 report from Papua New Guinea stated that CTVT was "endemic before the advent of the white man" [39]. Two reports published in the 1950s noted declines in CTVT prevalence, stating that CTVT occurs "less commonly in London dogs" (1954) [40] and that there has been a "reduction in incidence" of CTVT in New York City (1951) [41]. Indeed, our literature review documented a clear decline in
CTVT in the United Kingdom during the twentieth century (see Additional file 3).

Eighteen of the published reports provided a numerical value for the prevalence of naturally occurring CTVT in their study (see Additional file 4). The reported prevalence of CTVT in affected populations ranged from $1 \%$ or less (Jamaica, 1968 [42]; Kenya, 1972 [43]; Bangladesh, 2010 [44]) to almost 20\% (Papua New Guinea, 1985 [45] and 1986 [46]; Mexico 2007 [47] and 2010 [48]).

\section{Current worldwide CTVT distribution}

We designed and distributed an internet-based questionnaire with 18 predominantly multiple choice questions regarding CTVT prevalence, features of CTVT-infected dogs and conditions of local dog populations to more than one thousand veterinarians and animal health workers in 164 countries (full questionnaire is available in Additional file 5). Respondents were asked to estimate the prevalence of CTVT in their local area. We received a total of 645 completed questionnaires from 109 countries.

The average estimated CTVT prevalence reported for each country from which a minimum of three responses were received is displayed in Figure 2A (see also Additional file 6). In addition, a separate map displays each individual respondent's estimate of CTVT prevalence (see Additional file 7). The data indicate that CTVT is estimated to occur at between one and ten percent prevalence in dogs in most countries in South and Central America as well as in parts of Africa and Asia. The average reported prevalence by continent is shown in Figure 2B. The highest estimated CTVT prevalence that we recorded was in Belize, where the average CTVT prevalence (calculated from 6 responses) was estimated to be between 10 and 20 percent. Several countries (Canada, the Czech Republic, Finland, the Netherlands, New Zealand, Sweden, Switzerland and the United Kingdom) were consistently reported by all respondents from that country to be free of endemic CTVT; in these countries, the only CTVT cases were specifically reported to be imported from abroad (see also Figure 2A and Additional file 7). CTVT was reported as absent from 


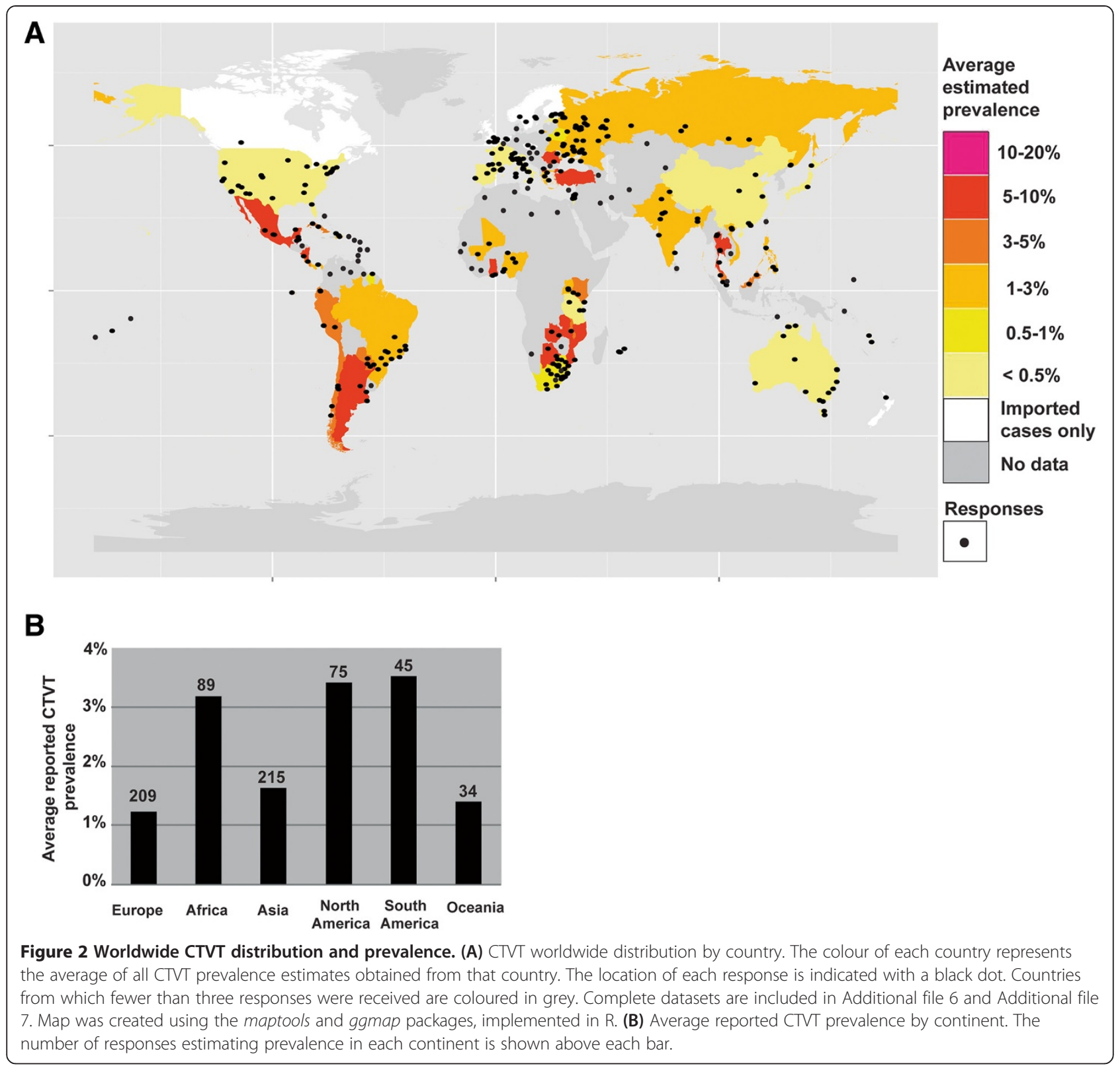

many regions of the United States and Australia, but was present in remote indigenous communities, including Indian reservations in Arizona and North Dakota, as well as in Australian Aboriginal communities in the Northern Territory and Western Australia (see Additional file 7). There was also geographical variation in estimated CTVT prevalence in Europe; the disease was reported to be absent except for occasional imported cases in many countries of Northern and Western Europe, but was estimated to be present at less than ten percent prevalence in countries in Southern and Eastern Europe (see Additional file 7).

\section{Status of dogs with CTVT}

We asked questionnaire respondents to report the most likely gender and health status of animals with CTVT. Despite previous suggestions that CTVT is more common in males [49,50] or females [51-55], responses to the questionnaire indicated that there is no universal gender bias for CTVT infection, with 144 respondents reporting that CTVT was more common in males, 146 reporting that it was more common in females and 168 claiming that it was equally common in both sexes (chisquared test for no gender difference, $\mathrm{p}=0.907$ ) (Figure 3A). The majority of respondents (459 out of 637) claimed that 
A

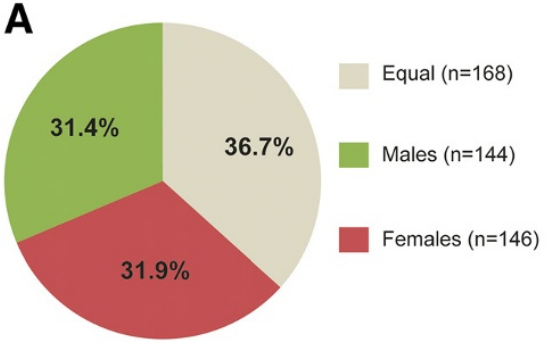

B

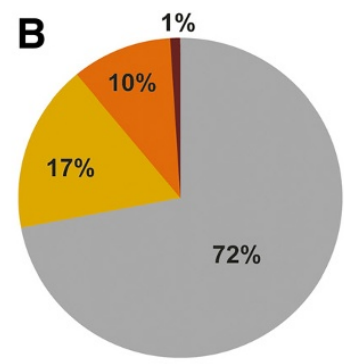

C

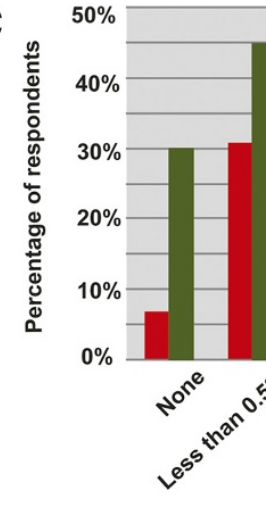

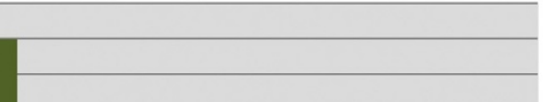

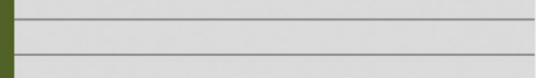

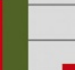

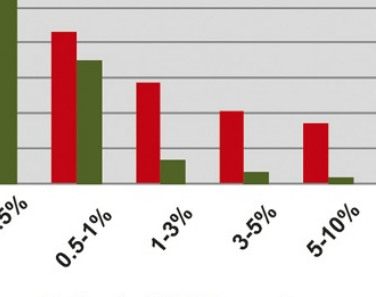

Estimated CTVT prevalence
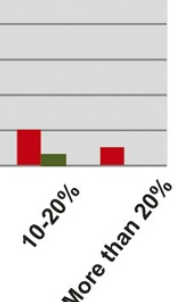

Entire

Spayed/neutered

Figure 3 Status of dogs with CTVT. (A) Gender of dogs infected with CTVT. Respondents were asked if they observed CTVT "more commonly in males", "more commonly in females" or "equally in males and females". The numbers refer to the number of respondents choosing each option. (B) Health condition of dogs infected with CTVT. Respondents were asked to report on the condition of the majority of CTVT-infected dogs by selecting one of the four categories shown. The numbers refer to the number of respondents choosing each option. (C) Relationship between spaying/neutering and CTVT prevalence. CTVT prevalence estimates from respondents who claimed that the majority of dogs in their area were spayed/neutered (total of 120 respondents) or entire (total of 340 respondents) are coloured in red and green respectively. Percentage of respondents refers to the proportion of respondents choosing each option.

dogs with CTVT were otherwise healthy rather than infected with parasites or otherwise diseased, thin or emaciated, or carrying injuries or bite marks (Figure 3B). We investigated the association of spaying/neutering with CTVT presence by asking respondents whether the majority of dogs in their country are spayed/neutered or entire. The responses showed that higher estimated CTVT prevalence coincides with higher percentage of respondents claiming that the majority of dogs are entire rather than spayed or neutered (Figure 3C).

Despite previous reports of successful experimental transmission of CTVT into wild canids, including wolves, coyotes and red foxes [3,30,56-58], no naturally occurring CTVT case has been previously reported in a wild canid. We further investigated this by asking all questionnaire respondents if they had observed CTVT in a wild canid (see Additional file 5). The responses did not reveal any confirmed reports of CTVT in wild canid populations.

\section{Factors influencing CTVT prevalence}

We next stratified countries based on income economy (The World Bank, Country and Lending Groups [59]) and found strikingly lower estimated prevalence of CTVT in countries with high income economies, compared with those with low, lower-middle and upper-middle income economies, which had similar distributions of estimated CTVT prevalence (Figure 4A). The proportion of countries with reported presence of free-roaming dogs was also associated with income economy category (Figure 4B), presenting the possibility that differences in presence of free-roaming dogs may explain the link between CTVT prevalence and national development status.

Additionally, we observed a weak negative correlation between average reported CTVT prevalence and socioeconomic status, determined by Gross Domestic Product (GDP) per capita value for each country (see Additional file 8, Pearson's correlation two tailed test between CTVT prevalence and GDP values, $\mathrm{r}=-0.504, \mathrm{p}=4.52 \times 10^{-5}$ ), together with a weak negative correlation between average reported CTVT prevalence and distance from the equator, as measured by distance from the equator to the capital city of each country (see Additional file 8, Pearson's correlation two tailed test between CTVT prevalence and distance from the equator, $\left.\mathrm{r}=-0.416, \mathrm{p}=8.39 \times 10^{-4}\right)$. It is possible, however, that these correlations, as well as a previously identified correlation between CTVT prevalence and distance from the equator within the United States [60], may be explained by the presence of free-roaming dogs. 

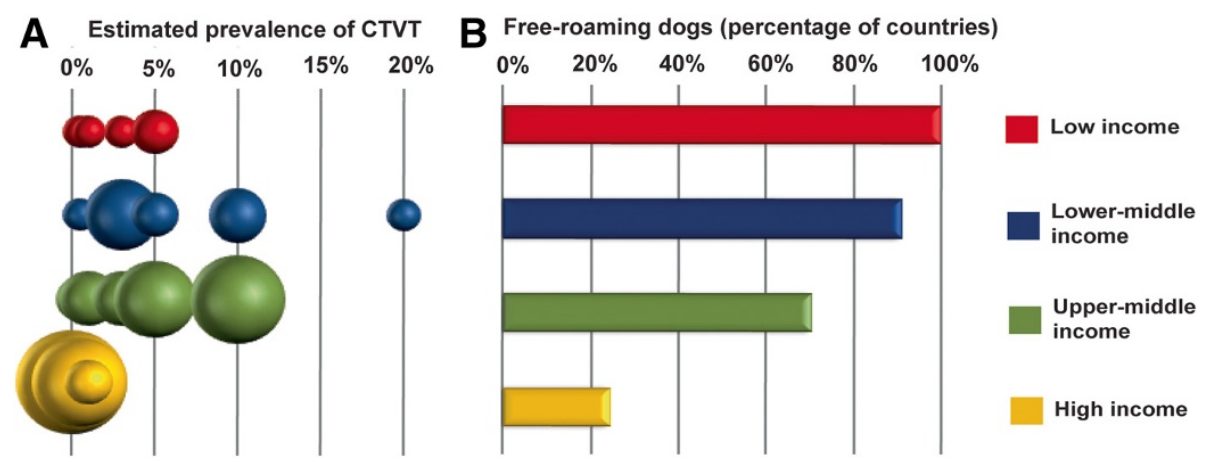

Figure 4 Factors associated with CTVT prevalence. (A) Relationship between CTVT prevalence and socio-economic status defined as low/ lower-middle/upper-middle/high income economies (World Bank, Country and Lending Groups [59]). The size of the dots represents the number of countries with estimated average CTVT prevalence within each interval. CTVT prevalence values represent the upper limit of each categorical interval. (B) Relationship between socio-economic status defined by division into low/lower-middle/upper-middle/high income economies and presence of free-roaming dogs, as reported by respondents to the questionnaire. "Percentage of countries" refers to the proportion of countries within each income category in which the presence of free-roaming dogs was reported by the majority of respondents.

\section{Metastasis and treatment of CTVT}

CTVT metastasis has been previously noted in individual case reports [43,50,52,54,61-86]. We asked questionnaire respondents to estimate the proportion of CTVT cases in which metastasis is observed. Of the six categorical intervals available to respondents ("none", "0-5\%", "5-10\%", "10-15\%", "15-20\%", "more than 20\%"), the majority of respondents estimated that metastasis occurs in 0-5 percent of CTVT cases (Figure 5A), consistent with previously published estimates [1,49]. Additionally, we recorded the most commonly observed sites of metastasis reported by questionnaire respondents (Figure 5B).

Vincristine is known to be a very effective treatment for CTVT [49,53,87-90]. We asked respondents to report the type and effectiveness of treatments they typically administer for CTVT (Figure 5C). The majority of respondents (373 out of 454 respondents, $82.2 \%$ ) reported that they use either vincristine alone or vincristine in combination with surgery, doxorubicine or radiotherapy. A proportion of respondents $(10.9 \%, 50)$ reported that they used surgery alone or other non-vincristine treatments $(4 \%, 18)$. Thirteen $(2.9 \%)$ respondents stated that the only option is euthanasia. Those who used vincristine treatment for CTVT reported that 80 to 100 percent of tumours usually went into complete remission after treatment (Figure 5D), however the number of vincristine doses claimed to be required for complete remission varied between respondents. This contrasted with the poor reported effectiveness of surgery alone or other nonvincristine treatments (Figure 5D).

\section{Discussion}

This survey of current and historical CTVT distribution patterns confirms that CTVT was and remains a very common canine infectious disease throughout the world. The global CTVT prevalence data reported in this study are individual estimates of local CTVT prevalence and are thus subject to errors introduced by variation in methodologies used by respondents to estimate prevalence (see Methods). Difficulties in prevalence estimation may have been further confounded by a combination of absent, inconsistent or incomplete record keeping, personal biases as well as systematic biases introduced where the sampling population was not representative of the population as a whole. Furthermore, variation in CTVT prevalence due to seasonal, demographic or local geographical factors may not have been captured by our approach. In order to minimise the effects of estimate biases on our analysis, we only included data from countries from which we received at least three responses in Figure 2A and Figure 4. Despite the limitations associated with estimating global CTVT prevalence, our large sample size supports the conclusion that a strikingly large proportion of the global dog population harbours CTVT infection at a prevalence of between 0.5 and 10 percent. Future studies will be important to further validate global variation in CTVT prevalence.

We have documented the decline and disappearance of CTVT from the United Kingdom during the twentieth century (Figure 6 and Additional file 3). The eradication of CTVT from the United Kingdom may be due to the introduction of a series of dog management laws throughout the nineteenth and twentieth centuries (Figure 6). The Dogs Act, 1871 [91] imposed civil responsibility on dog owners and stated that dogs must be "under proper control" and "stray dogs may be detained and sold or destroyed". This was followed by the Dogs Act 1906 [92], amended in 1928 and 1938, which introduced a requirement to report stray dogs to the police. It is striking that the eradication of CTVT, once a common canine pathogen in the United Kingdom (see Additional file 3), appears to have occurred as an unintentional result of human intervention. 


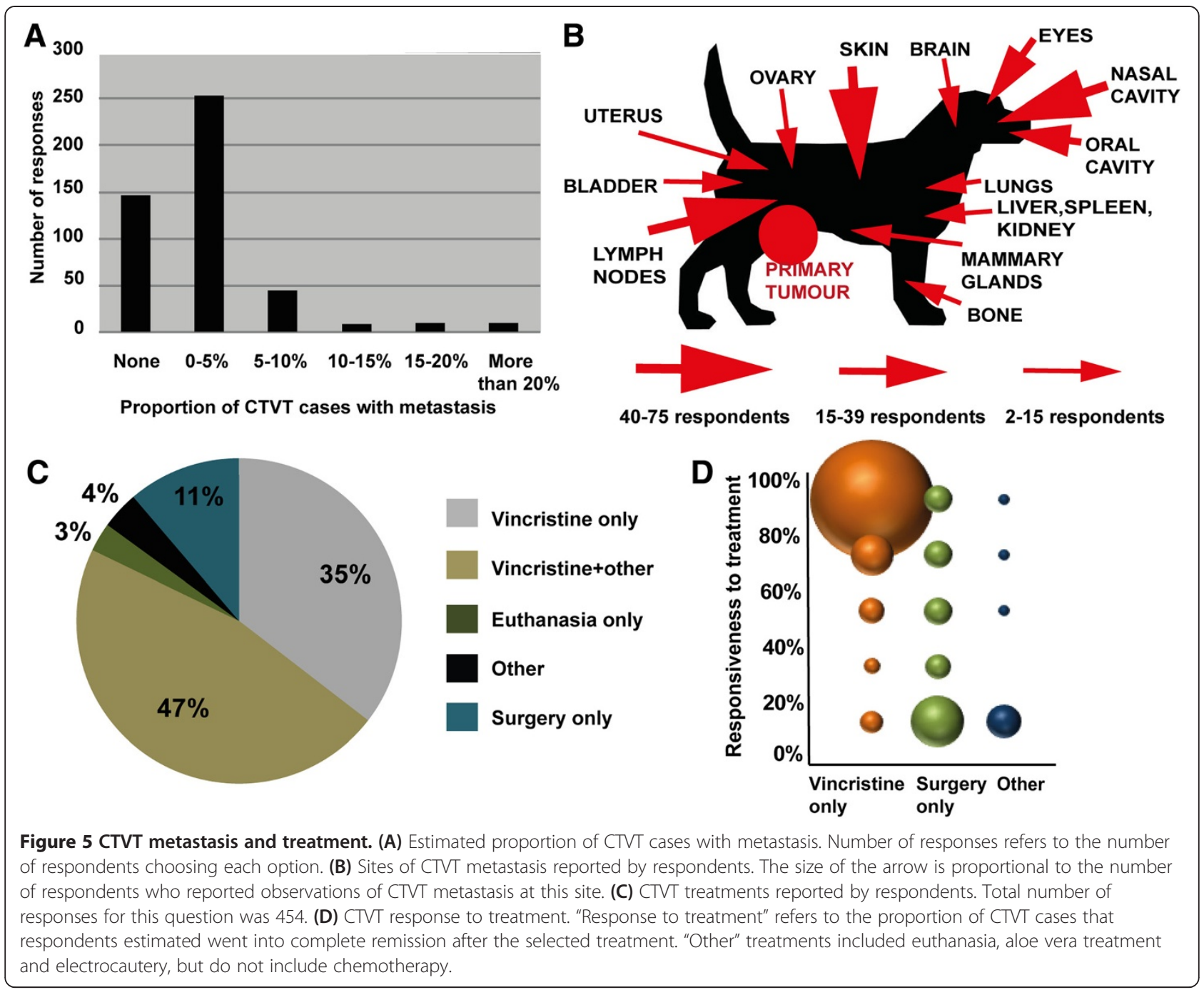

The importance of dog management and spaying/neutering in CTVT control was highlighted by a respondent from Koh PhaNgan Island, Thailand, where breeding control and sterilisation campaigns have almost eradicated CTVT from the island since the commencement of the sterilisation project in 2001. Several respondents, however, when asked to comment on any unusual cases of CTVT that they had seen, commented that they had observed CTVT in dogs years after spay or neuter surgery. This suggests that either the latent period for CTVT development, which previous anecdotal reports have suggested may last for weeks or months $[2,55,93]$, can sometimes last years, or, alternatively, that spaying and neutering does not always protect dogs from CTVT. Furthermore, non-coital modes of CTVT transmission, including biting, licking or sniffing, may also contribute to CTVT infection of spayed/neutered dogs [68,94-98].

Despite the widespread presence of CTVT in dog populations worldwide, the results of our survey indicate that its prevalence rarely rises above $10 \%$ (Figure 2). This contrasts with epidemiological patterns observed for the only other known naturally occurring transmissible canPrevalence of DFTD usually rises above $50 \%$ in affected Tasmanian devil populations and the disease usually triggers a rapid population decline (reviewed in [99]). Given that the mixed mating system of dogs would promote widespread exposure to the disease [100], this pattern suggests that only a proportion of the dog population may be susceptible to CTVT at any one time and, possibly, as one early report of CTVT proposed, that "some animals are naturally refractory" to infection [5]. Future studies of CTVT exposure and susceptibility in free-roaming dog populations may reveal further insights into the biological basis of this interesting observation.

Genetic studies indicate that the global spread of CTVT has occurred relatively recently in the history of cer, the Tasmanian devil facial tumour disease (DFTD). 


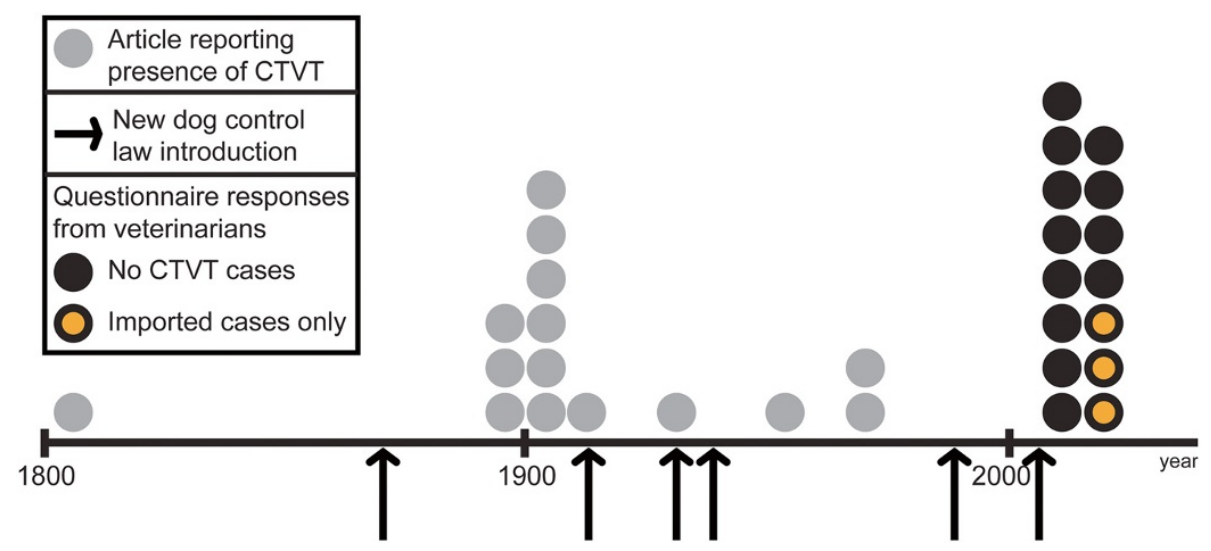

Figure 6 Disappearance of CTVT from the United Kingdom during the twentieth century. Timeline showing the declining number of historical reports of CTVT in the United Kingdom, coinciding with the introduction of dog laws. Data from the questionnaire (indicated with black and yellow dots) were used to confirm current absence (except for occasional imported cases) of CTVT from the United Kingdom. See also Additional file 3.

the lineage, probably within the last 500 years [13-15]. Although we do not know the location in which CTVT first emerged, our study has highlighted the remarkable efficiency with which CTVT has colonised its global host population. We obtained evidence for CTVT's presence in some of the world's most isolated communities and islands, including the Solomon Islands, Samoa, American Samoa, Fiji, Reunion, Mauritius and several islands in Micronesia. In contrast, New Zealand is free of CTVT, likely due to its rigorous import quarantine rules [101]. Together, these findings highlight the mobility of dogs, which, alongside humans, have travelled rapidly and extensively around the globe.

This study has provided information on historical and current CTVT global distribution and prevalence and has illuminated a number of factors which may influence CTVT prevalence, including presence of free-roaming dogs, dog spay/neuter practices and enforcement of dog control laws. In addition to providing insight into the global spread of a unique type of pathogen, this study may assist policy-makers and veterinarians in the development of measures to more effectively control and reduce CTVT prevalence and prevent further spread of the disease.

\section{Conclusions}

Our results provide a survey of the current global distribution of CTVT, confirming that CTVT is endemic in at least 90 countries worldwide. Additionally, our analysis highlighted factors that continue to modify CTVT's prevalence around the world; free-roaming dogs were implicated as a reservoir for the disease and spaying and neutering were associated with lower CTVT prevalence. Our analysis also documents the disappearance of the disease from the United Kingdom during the twentieth century, which may have been an unintentional result of the introduction of dog control policies. In addition to providing insights into the global spread of a unique canine infectious disease, this study may assist veterinarians and policy-makers to develop measures to more effectively control and reduce CTVT prevalence and spread.

\section{Methods}

This study was approved by the Department of Veterinary Medicine, University of Cambridge, Ethics and Welfare Committee (reference number CR105). The questionnaire used in this study is available in supplementary materials (see Additional file 5). Potential participants were selected with an internet-based search. The questionnaire was sent by email to 1025 individuals and distributed at several veterinary conferences. The questionnaire was also circulated in several veterinary societies' mailing lists and published in veterinary periodicals, newsletters and on social media sites. Of the 645 completed questionnaires received, nine respondents provided information about more than one country. Most of the respondents were private veterinarians $(415,64.3 \%)$ or veterinarians working at veterinary schools $(143,22.2 \%)$, but they also included other individuals working at charitable organisations $(50,7.8 \%)$, government (16, 2.5\%), pathology laboratories (13, 2.0\%) and research agencies $(8,1.2 \%)$. All of the respondents completed the questionnaire within days or weeks of receiving it. The questionnaire was made available in English, Chinese, French, Portuguese, Spanish and Russian.

The estimated average CTVT prevalence for each country was determined using the average of the mid-point values for each reported prevalence category received from each country. Only countries with three or more responses were included in the analyses in Figures 2A and 4, 
but all responses are shown in Additional file 6 and Additional file 7. Previous studies indicated that CTVT prevalence rarely rises above 20 percent (see Additional file 4), therefore the prevalence categories available in the questionnaire were "none", "less than 0.5\%", "0.5-1\%", "1-3\%", "3-5\%", "5-10\%", "10-20\%" and "more than $20 \%$ ". The CTVT prevalence figures reported here were estimated by respondents based on (1) an estimate of the number of CTVT patients as a proportion of total canine patients in general clinical practice; (2) an estimate of the total number of CTVT diagnostic samples as a proportion of the total number of canine diagnostic samples passing through a pathology laboratory; (3) a personal estimate based on previous veterinary experience and discussions with veterinary colleagues; and (4) the total number of CTVT cases in populations of dogs participating in spay/neuter campaigns.

The World Atlas [102] was used to generate the list of countries in Additional file 6, and Taiwan and Reunion were added as separate countries. Data on the distance from the equator and GDP values were obtained from News Track India [103] and the International Monetary Fund [104] respectively. Distance from the equator for each country refers to the distance of the capital city from the equator. Countries were classified as low income, lower-middle income, upper-middle income and high income economies based on the classification scheme defined by the World Bank [59].

\section{Additional files}

Additional file 1: Contemporary and historical reports of naturally occurring CTVT cases in the published literature. Reports are ordered by date. Multiple reports from the same publication are indicated on separate lines. Only reports referring to primary naturally occurring CTVT cases are included, while articles reporting only cases of experimentally transplanted CTVT are excluded.

Additional file 2: Global distribution of published reports of CTVT. Locations in which naturally occurring CTVT cases are reported in the published literature are indicated on the map, classified by date of report. Bibliographical information for each case is found in Additional file 1. The two reports in Canada $[5,105]$ were specified as imported cases from abroad and are marked with *. Map was created using Adobe Illustrator

Additional file 3: Historical reports confirming presence of CTVT in the United Kingdom in the 19th and 20th centuries. The comments were obtained from articles published between 1810 and 1969 .

Additional file 4: Contemporary and historical reports providing a numerical value for CTVT prevalence.

Additional file 5: Text version of CTVT questionnaire used in this study.

Additional file 6: Summary of CTVT prevalence data by country.

Additional file 7: Worldwide CTVT distribution and prevalence. (A) Map indicating CTVT prevalence estimated by each respondent. Each response is represented by a single coloured dot. Map was created using Adobe lllustrator. (B) Higher magnification map showing detailed distribution of CTVT prevalence estimates in Europe. Map was created using Adobe lllustrator.

Additional file 8: Socio-economic and climatic factors associated with CTVT prevalence. (A) Relationship between estimated CTVT prevalence and Gross Domestic Product (GDP) per capita values in US dollars. Prevalence values displayed represent the higher limit of each categorical interval. Each dot represents the average of three or more estimated prevalence values received from that country. A line of best fit is displayed $\left(R^{2}=0.2543\right)$. (B) Relationship between estimated CTVT prevalence and geographical latitude displayed as distance from the equator (in degrees of latitude) measured for the capital city of each country. Prevalence values displayed represent the higher limit of each categorical interval. Each dot represents the average of three or more estimated prevalence values received from that country. A line of best fit is displayed $\left(R^{2}=0.1727\right)$.

\section{Competing interests}

The authors declare that they have no competing interests.

\section{Authors' contributions}

AS conceived and designed the study, performed the study, analyzed the data and wrote the paper. EPM conceived and designed the study, performed the study, wrote the paper and acted as the first author's study supervisor. Both authors read and approved the final manuscript.

\section{Acknowledgements}

We thank all the participants who completed the questionnaire. We are grateful to David Wedge and Simon Frost for assistance with statistical analysis and helpful discussions. Michelle Morters, Darryn Knobel, Kati Loeffler, Mike Hobart and John Cooper assisted with questionnaire design and Viktor Azariev, Lena Borise, Serge Dronov, Jorge Soares, Lenka Strakova, Darren Xu, Angie Yan, Zijun Yu and Jorge Zamora assisted with questionnaire translation. We also thank the following individuals for providing useful information: Karen Allum, Leontine Bansse-Issa, Deborah Bauer, Cristobal Briceno, Cinzia Cantacessi, Shevaun Gallwey, Olga Glebova, Natalia Ignatenko, Mayra Martinez, J. Weldon McNutt, Fanny Gallardo de Medrano, Clement Meseko, Ahne Simonsen, Adam Wagner and Mirjam van der Wel. We thank Karina Ferreira de Castro and Fanny Gallardo de Medrano for providing the CTVT photos used in Figure 1. We are grateful to Andrew King at the Wellcome Trust Sanger Institute Library for assistance with obtaining papers. We are grateful to the following organisations for distributing the questionnaire and providing valuable information: Veterinary Society of Surgical Oncology (VSSO), Veterinary Cancer Society, World Vets, Animal Balance, The Spanky Project, Humane Society Veterinary Medical Association-Rural Area Veterinary Services (HSVMA-RAVS), World Small Animal Veterinary Association (WSAVA), WWBNSF Canada, Israel Veterinary Medical Association, Italian Veterinary Oncology Society, American College of Veterinary Internal Medicine (ACVIM), Rural Vets South Africa, MИP BETEPИHAPИИ (World Veterinary Medicine) newsletter, the veterinary periodical VetPharma, organisers of the Nigerian Veterinary Medical Association Annual Congress in Ado-Ekiti, IX National Conference on Cancer in Small Animals in Moscow, XII International Scientific-Practical Conference Veterinary Centre "Alden-Vet" and International Dermatology Symposium 2013 in St. Petersburg. The dog silhouette in Figure 5B is reproduced from Wikimedia Commons (Dog silhouette.svg by Abujoy, licensed under CC-BY-SA-2.5; http://commons.wikimedia.org/wiki/File:Dog_silhouette. svg\#filelinks). Support for this project was provided by King's College, Cambridge and Newnham College, Cambridge.

Received: 24 March 2014 Accepted: 18 July 2014

Published: 3 September 2014

\section{References}

1. Karlson AG, Mann FC: The transmissible venereal tumor of dogs: observations on forty generations of experimental transfers. Ann N Y Acad Sci 1952, 54(6):1197-1213.

2. Smith GB, Washbourn JW: Infective venereal tumours in dogs. J Pathol Bacteriol 1898, 5:99-110.

3. Cohen D: The canine transmissible venereal tumor: a unique result of tumor progression. Adv Cancer Res 1985, 43:75-112.

4. Powell White C: Contagious growths in dog. Br Med J 1902, 2:176-177.

5. French C: Surgical Diseases and Surgery of the dog, Washington DC. 1906:254-256. 286-287 and 365-367.

6. Hobday F: Operations on the Genital Organs. In Canine and Feline Surgery. Edited by W\&AK Johnston. 1900:126-127. 
7. Das U, Das AK: Review of canine transmissible venereal sarcoma. Vet Res Commun 2000, 24(8):545-556.

8. Stimmelmayr R: Transmissible venereal tumor: a special canine case of contagious cancer cells. Vet Times 2010, 14-19.

9. Ganguly B, Das U, Das AK: Canine transmissible venereal tumour: a review. Vet Comp Oncol 2013, doi:10.1111/vco.12060.

10. Eze CA, Anyanwu HC, Kene ROC: Review of Canine Transmissible Venereal Tumour (TVT) in Dogs. Nigerian Vet J 2007, 28(1):54-70.

11. Stookey JL: Transmissible venereal tumors of dogs. Nat/ Cancer Inst Monogr 1969, 32:315-320.

12. Purohit GN: Canine transmissible venereal tumor: a review. I J Vet Med 2009, 6: doi:10.5580/a5586a.

13. Murgia C, Pritchard JK, Kim SY, Fassati A, Weiss RA: Clonal origin and evolution of a transmissible cancer. Cell 2006, 126(3):477-487.

14. Rebbeck CA, Thomas R, Breen M, Leroi AM, Burt A: Origins and evolution of a transmissible cancer. Evol Int J Org Evol 2009, 63(9):2340-2349.

15. Murchison EP, Wedge DC, Alexandrov LB, Fu B, Martincorena I, Ning Z, Tubio JM, Werner El, Allen J, De Nardi AB, Donelan EM, Marino G, Fassati A, Campbell PJ, Yang F, Burt A, Weiss RA, Stratton MR: Transmissible dog cancer genome reveals the origin and history of an ancient cell lineage. science 2014, 343(6169):437-440.

16. Vermooten MI: Canine transmissible venereal tumor (TVT): a review. J S Afr Vet Assoc 1987, 58(3):147-150.

17. Gradoni L: Epidemiological surveillance of leishmaniasis in the European Union: operational and research challenges. Euro Surveill 2013, 18(30):20539.

18. Angell JW, Duncan JS, Carter SD, Grove-White DH: Farmer reported prevalence and factors associated with contagious ovine digital dermatitis in Wales: a questionnaire of 511 sheep farmers. Prev Vet Med 2014, 113(1):132-138.

19. Alvar J, Velez ID, Bern C, Herrero M, Desjeux P, Cano J, Jannin J, Den Boer M, Team WHOLC: Leishmaniasis worldwide and global estimates of its incidence. PLoS One 2012, 7(5):e35671.

20. Kretzschmar M, Mangen MJ, Pinheiro P, Jahn B, Fevre EM, Longhi S, Lai T, Havelaar AH, Stein C, Cassini A, Kramarz P, Consortium BC: New methodology for estimating the burden of infectious diseases in Europe. PLoS Med 2012, 9(4):e1001205.

21. Chapman AL, Darton TC, Foster RA: Managing and monitoring tuberculosis using web-based tools in combination with traditional approaches. Clin Epidemiol 2013, 5:465-473.

22. Milinovich GJ, Williams GM, Clements AC, Hu W: Internet-based surveillance systems for monitoring emerging infectious diseases. Lancet Infect Dis 2013, 14(2):160-168.

23. Blaine DP: A Domestic Treatise on the Diseases of Horses and Dogs London T Boosey. 1810.

24. Beebe SP, Ewing J: A study of the so-called infectious lymphosarcoma of dogs. J Med Res 1906, 15(2):209-228. 205.

25. Beebe SP: The growth of lymphosarcoma in dogs-summary of recent observations. JAMA 1907, 49(18):1492-1493.

26. Borrel MA: Lymphosarcome du chien. Sem Med (Paris) 1907, 27:94-95

27. Sticker A: Ueber den Krebs der Thiere. Arch Klin Chir 1902, 65:1023-1087.

28. Sticker A: Transplantables Lymphosarcom des Hundes. Z Krebsforsch 1904, 1:413-444

29. Sticker A: Ubertragung von Tumoren bei Hunden durch den Geschlechtsakt. Berl Tier Woschr 1906, 50(894-995):894.

30. Sticker A: Transplantables Rundezellensarkom des hundes Ein beitrag zer Lehre der Krebsubertragbarkeit. Z Krebsforsch 1906, 4:227-314

31. Sticker A: Endemischer Krebs. Z Krebsforsch 1907, 5(2):215-224

32. Bergell $P$, Sticker A: Ueber Pathogenese und uber den spezifischen Abbau der Krebsgeschwulste. Dtsch Med Wochenschr 1907, 2(38):1521-1522.

33. Von Bergmann E: Gelungene Carcinomubertragung beim Hunde. Centralb/ Chir 1895, 27:XXIV. Kongress.

34. Duplay S: Tumeurs expérimentales chez les animaux. Atti dell'XI Congresso Medico Internazionale Roma 1894, 2:103-104.

35. Hobday F: Observations on contagious venereal tumours in canine patients. Vet J 1905, 2:342-346.

36. Smith GB, Washbourn JW: Pathological society of London. Meeting held on 6th April. Lancet 1897, 10:1025-1026.

37. Hobday F: Surgical Diseases of the dog and cat and Anaesthetics (Second Edition). 8 Henrietta Street: Bailliere, Tindall and Cox; 1906:266-270. and 291-292.

38. Matsui Y: Uber transplantable-sarcomatige Neubildung des Hundes. Gann 1909, 4:123.
39. Seligmann CG: On the Occurrence of new Growths Among the Natives of British New Guinea. Pathological Section: Royal Society of Medicine; 1908

40. Cotchin E: Neoplasia in the dog. Vet Rec 1954, Twelfth Congress paper, December 25th:879-885.

41. Bloom F, Paff GH, Noback CR: The transmissible venereal tumor of the dog; studies indicating that the tumor cells are mature end cells of reticulo-endothelial origin. Am J Pathol 1951, 27(1):119-139.

42. Thorburn MJ, Gwynn RV, Ragbeer MS, Lee BI: Pathological and cytogenetic observations on the naturally occurring canine venereal tumour in Jamaica (Sticker's tumour). Br J Cancer 1968, 22(4):720-727.

43. Rottcher D: Clinical features and pathology of transmissible venereal tumours in dogs in Kenya. Tierarztl Umsch 1972, 27:235-238.

44. Tarafder A, Samad MA: Prevalence of clinical diseases of pet dogs and risk perception of zoonotic infection by dog owners in Bangladesh. Bangl J Vet Med 2010, 8(2):163-174.

45. Hamir AN: Primary penile and nasal transmissible venereal tumours in a dog. Aust Vet J 1985, 62(12):430-432.

46. Hamir AN: Neoplasms of dogs in Papua New Guinea. Aust Vet J 1986, 63(10):342-343

47. Ortega-Pacheco A, Segura-Correa JC, Jimenez-Coello M, Linde Forsberg C: Reproductive patterns and reproductive pathologies of stray bitches in the tropics. Theriogenology 2007, 67(2):382-390.

48. Cruz JC: Canine transmissible venereal tumor in the metropolitan area of Mexico City. Rev Cient 2010, 20(4):362-366.

49. Brown NO, Calvert C, MacEwen EG: Chemotherapeutic management of transmissible venereal tumors in 30 dogs. J Am Vet Med Assoc 1980, 176(10 Pt 1):983-986.

50. Osipov NE, Golubeva VA: Diagnosis and treatment of transmissible sarcoma of dogs. Veterinaria 1976, 7:97-98.

51. Sobral RA: Occurrence of canine transmissible venereal tumor in dogs from the Jaboticabal region. Brazil Ars Veterinaria 1998, 14(1):1-10.

52. Ajello P: Il tumore di Sticker. Annali Facolta Medicina Veterinaria Mes 1980, 17:289-339.

53. Singh J, Rana JS, Sood N, Pangawkar GR, Gupta PP: Clinico-pathological studies on the effect of different anti-neoplastic chemotherapy regimens on transmissible venereal tumours in dogs. Vet Res Commun 1996, 20(1):71-81.

54. Gandotra VK: Occurrence of canine transmissible venereal tumor and evaluation of two treatments. Ind Vet J 1993, 70:854-857.

55. Ajello P: Osservazioni sul Tumore Genitale Contagioso del Cane. PhD Thesis, Universita di Messina, Facolta do Medicina Veterinaria. 1939.

56. Cockrill JM, Beasley JN: Transmission of transmissible venereal tumor of the dog to the coyote. Am J Vet Res 1979, 4:409-410.

57. Dungern V: Zur Biologie des Rundezellensarkom des Hundes. Munch Med Wochenschr 1912, 5:238.

58. Wade $\mathrm{H}$ : An experimental investigation of infective sarcoma of the dog, with a consideration of its relationship to cancer. J Pathol Bacteriol 1908, 12:384-425.

59. The World Bank: Country and Lending Groups, 2013 Accessed 12th March 2013. http://data.worldbank.org/about/country-and-lending-groups\#LLow_income.

60. Hayes HM Jr, Biggar RJ, Pickle LW, Hoover R, Toft JD 2nd: Canine transmissible venereal tumor: a model for Kaposi's sarcoma? Am J Epidemiol 1983, 117(1):108-109.

61. Higgins DA: Observations on the canine transmissible venereal tumour as seen in the Bahamas. Vet Rec 1966, 79(3):67-71.

62. Kimeto B, Mugera GM: Transmissible veneral tumour of dog in Kenya. Bull Epizoot Dis Afr 1974, 22(4):327-329.

63. Abuom TO: Transmissible venereal tumor with subcutaneous and bone metastasis in a Dog. Kenya Vet 2006, 30(1):11-13.

64. Adams EW, Slaughter LJ: A canine venereal tumor with metastasis to the brain. Pathol Vet 1970, 7(6):498-502

65. Barron CN, Saunders LZ, Seibold HR, Heath MK: Intraocular tumors in animals. V. Transmissible venereal tumor of dogs. Am J Vet Res 1963, 24:1263-1270.

66. Bastan A: Uterine and ovarian metastasis of transmissible venereal tumor in a bitch. Turk J Vet Anim Sci 2008, 32(1):65-66.

67. Belkin PV: Extragenital venereal granuloma in the abdominal organs of a dog. J Am Vet Med Assoc 1959, 135:575-576.

68. Chikweto A: Genital and extragenital canine transmissible venereal tumor in dogs in Grenada, West Indies. Open J Vet Med 2013, 3:111-114.

69. Feldman WH: So called infectious sarcoma of the dog in an unusual anatomic situation. Am J Pathol 1929, 5:183-195. 
70. Gurel A: Transmissible venereal tumors detected in the extragenital organs of dogs. Israel J Vet Med 2002, 57(2):1-8.

71. Idowu L: The chromosomes of the transmissible venereal tumour of dogs in Ibadan, Nigeria. Res Vet Sci 1977, 22(3):271-273.

72. Levy E, Mylonakis ME, Saridomichelakis MN, Polizopoulou ZS, Psychogios V, Koutinas AF: Nasal and oral masses in a dog. Vet Clin Pathol 2006, 35(1):115-118

73. Manning PJ, Martin PD: Metastasis of canine transmissible venereal tumor to the adenohypophysis. Pathol Vet 1970, 7(2):148-152.

74. Moulton JE: Tumours of Domestic Animals. 10th edition. Berkeley and Los Angeles: University of California Press; 1990:498-502.

75. Mylonakis ME, Saridomichelakis MN, Lazaridis V, Leontides LS, Kostoulas P, Koutinas AF: A retrospective study of 61 cases of spontaneous canine epistaxis (1998 to 2001). J Small Anim Pract 2008, 49(4):191-196.

76. Ferreira AJ, Jaggy A, Varejao AP, Ferreira ML, Correia JM, Mulas JM, Almeida O, Oliveira P, Prada J: Brain and ocular metastases from a transmissible venereal tumour in a dog. J Small Anim Pract 2000, 41(4):165-168.

77. Miller WW: Ocular metastasis of a transmissible venereal tumor. Canine Pract 1990, 15(3):19-21.

78. Park MS, Kim Y, Kang MS, Oh SY, Cho DY, Shin NS, Kim DY: Disseminated transmissible venereal tumor in a dog. J Vet Diagn Invest 2006, 18(1):130-133.

79. Pereira JS, Silva AB, Martins AL, Ferreira AM, Brooks DE: Immunohistochemical characterization of intraocular metastasis of a canine transmissible venereal tumor. Vet Ophthalmol 2000, 3(1):43-47.

80. Prier JE, Johnson JH: Malignancy in a canine transmissible venereal tumor. J Am Vet Med Assoc 1964, 145:1092-1094.

81. Rust JH: Transmissible lymphosarcoma in the dog. J Am Vet Med Assoc 1949, 114(862):10-14.

82. Sastry GA, Narayana JV, Rao PR, Christopher J: A case of metastatic venereal tumour in a bitch. Indian Vet J 1965, 42(9):658-660.

83. Yang TJ: Metastatic transmissible venereal sarcoma in a dog. J Am Vet Med Assoc 1987, 190(5):555-556.

84. Cella F: Sopra un secondo caso di granuloma venereo del cane (c.d. sarcoma di sticker) osservato nell'Emilia - metastasi splenica. Nuova Veterinaria 1939, 12:217-220

85. Batista JS, Soares HS, Pereira RHMA, Petri AA, Sousa FDN, Nunes FCR: Canine transmissible veneral tumor with intra-ocular localization and spleen metastasis (Tumor venereo transmissivel canino com localizacao intra-ocular e metastase no baco). Acta Vet Brasilica 2007, 1:45-48.

86. Varughese EE, Singla VK, Ratnakaran U, Gandotra VK: Successful management of metastatic transmissible venereal tumour to skin of mammary region. Reprod Domest Anim 2012, 47(Suppl 6):366-369.

87. Nak D, Nak Y, Cangul IT, Tuna B: A Clinico-pathological study on the effect of vincristine on transmissible venereal tumour in dogs. $J$ Vet Med A Physiol Pathol Clin Med 2005, 52(7):366-370.

88. Calvert CA, Leifer CE, MacEwen EG: Vincristine for treatment of transmissible venereal tumor in the dog. J Am Vet Med Assoc 1982, 181(2):163-164.

89. Boscos C: Canine transmissible venereal tumor: clinical observations and treatment. Anim Familiaris 1988, 3:10-15.

90. Said RA, Silva LF, Albuquerque AROL, Sousa-Neta EM, Lavinsky MO: Efficacy and Side Effects of Vincristine Sulphate Treatment on Canine Transmissible Venereal Tumour. In Proceedings of the 34th World Small Animal Veterinary CongresS WSAVA. Sao Paulo: IVIS (International Veterinary Information Service); 2009. Available: [http://www.ivis.org/proceedings/wsava/2009/lecture30/14. pdf?la=1] Accessed 10th October 2013.

91. The Dogs Act, 1871. [http://www.legislation.gov.uk/ukpga/Nict/34-35/56/ introduction/enacted] Accessed on 12th August 2013.

92. The Dogs Act, 1906. [http://www.legislation.gov.uk/ukpga/Edw7/6/32/ contents] Accessed on 12th August 2013.

93. Locke KB, Yeh FJ, Hooper PT: Letter: transmissible venereal tumour in dogs in Australia. Aust Vet J 1975, 51(9):449.

94. Weir EC, Pond MJ, Duncan JR, Polzin DJ: Extragenital occurrence of transmissible venereal tumor in the Dog: literature review and case reports. J Am Anim Hosp Assoc 1978, 14:532-536.

95. Albanese F, Poli A, Millanta F, Abramo F: Primary cutaneous extragenital canine transmissible venereal tumour with Leishmania-laden neoplastic cells: a further suggestion of histiocytic origin? Vet Dermatol 2002, 13(5):243-246.

96. Guedes RMC, Nogueira RHG, Santos SRQ, Souza EM: Extragenital transmissible venereal tumor in a dog. Case report. Arq Bras Med Vet Zootec 1996, 48(3):369-374.
97. Ndiritu CG, Mbogwa SW, Sayer PD: Extragenitally located transmissible venereal tumor in dogs. Mod Vet Pract 1977, 58:940-946.

98. Perez J, Bautista MJ, Carrasco L, Gomez-Villamandos JC, Mozos E: Primary extragenital occurrence of transmissible venereal tumors: three case reports. Canine Pract 1994, 19(1):7-10.

99. Murchison EP: Clonally transmissible cancers in dogs and Tasmanian devils. Oncogene 2008, 27(Suppl 2):S19-S30.

100. Pal SK: Mating system of free-ranging dogs (canis familiaris). Int J Zool 2011, 2011.

101. Import Health Standards, Cats and Dogs. In CATDOGGEN, 4th April. 2013. [http://www.biosecurity.govt.nz/files/ihs/catdog.gen.pdf] Accessed on 20th June 2013.

102. The World Atlas: Countries Listed by Continent. [http://www.worldatlas.com/ cntycont.htm\#UlbgNL5wbmQ] accessed on 10th October 2012.

103. News Track India. 2011, Accessed on 11th March 2013 [http://www. newstrackindia.com/information/worldinfo/Latitude-and-Longitude-ofCountries.html]

104. The International Monetary Fund: World Economic Outlook Database. ; 2013. http://www.imf.org/external/pubs/ft/weo/2013/01/weodata/index.aspx.

105. Mikaelian I, Girard C, Ivascu I: Transmissible venereal tumor: a consequence of sex tourism in a dog. Can Vet J 1998, 39(9):591-591.

\section{doi:10.1186/s12917-014-0168-9}

Cite this article as: Strakova and Murchison: The changing global distribution and prevalence of canine transmissible venereal tumour. BMC Veterinary Research 2014 10:168.

\section{Submit your next manuscript to BioMed Central and take full advantage of:}

- Convenient online submission

- Thorough peer review

- No space constraints or color figure charges

- Immediate publication on acceptance

- Inclusion in PubMed, CAS, Scopus and Google Scholar

- Research which is freely available for redistribution 